\title{
Maternal and perinatal outcome of hypertensive disorders of pregnancy in a tertiary hospital of Kathmandu
}

\author{
Paudel N', Shrestha S'2, Parajuli P3
}

${ }^{1}$ Narayani Paudel, Assistant Professor, ${ }^{2}$ Santoshi Shrestha, Assistant Professor, ${ }^{3}$ Puspa Parajuli, Assistant Professor; Department of B.Sc. Nursing, Kathmandu Medical College Public Limited

\begin{abstract}
Background: Hypertensive disorders of pregnancy are considered to be a major worldwide health problem causing an increased risk of perinatal and maternal morbidity and mortality. Hypertensive disorders are the most common medical disorders encountered during pregnancy.

Objective: This study aimed to assess the maternal and perinatal outcome of hypertensive disorders in pregnancy. Methods: A hospital based prospective study was conducted in Obstetrics ward of Kathmandu Medical College Teaching Hospital. Total one hundred pregnant women admitted in antenatal ward with the diagnosis of hypertensive disorders in pregnancy were included in the study. A structured questionnaire was designed and data collection was done through one- to- one interview technique during the period of December 2015 to January 2017. The collected data were analyzed by using Statistical Package for Social Science version 20.

Results: Among 100 hypertensive disorders; $80 \%$ respondents had gestational hypertension, $16 \%$ had preeclampsia and two percent had eclampsia. Of total, $52 \%$ respondents had normal vaginal delivery followed by $46 \%$ caesarian section. One respondent had ante-partum hemorrhage, $11 \%$ had post-partum hemorrhage and one had developed hemolysis, elevated liver enzymes low platelets counts syndrome. Fortunately, no maternal mortality was occurred. Regarding perinatal outcome, $17 \%$ babies were born preterm, $13 \%$ babies had low birth weight and seven percent babies had birth asphyxia. Total five were stillbirths and one percent had early neonatal death.

Conclusion: Maternal outcome was good except few morbidities but perinatal outcome was found to be adverse. Proper management of hypertensive disorders is required to reduce perinatal morbidities and mortalities.
\end{abstract}

Key words: Eclampsia, Gestational hypertension, Maternal, Perinatal outcome, Preeclampsia

\section{INTRODUCTION}

Hypertension is the most common medical problem encountered during pregnancy occurring in approximately $7 \%-10 \%$ of all pregnancies ${ }^{1}$. Hypertensive disorders of pregnancy (HDP) are among the leading causes of maternal mortality, along with thromboembolism, hemorrhage and non-obstetric injuries. There are significant adverse maternal effects, some resulting in serious maternal morbidity and death. Maternal death is largely following complications from abruption placenta, hepatic rupture and eclampsia².

HDP are classified into 4 categories, as recommended by the National High Blood Pressure Education Program

Address for correspondence

Narayani Paudel

Assistant Professor, B. Sc. Nursing Department

Kathmandu Medical College, Kathmandu, Nepal

E-mail: paudelgn@gmail.com
Working Group on High Blood Pressure in Pregnancy: 1) chronic hypertension, 2) preeclampsia-eclampsia, 3) preeclampsia superimposed on chronic hypertension, and 4) gestational hypertension or pregnancy induced hypertension ${ }^{3}$.

Chronic hypertension is high blood pressure that precedes pregnancy, is diagnosed within the first 20 weeks of pregnancy, or does not resolve by the 12-week postpartum checkup. Gestational hypertension, formerly known as pregnancy-induced hypertension $(\mathrm{PIH})$, is the new onset of hypertension after 20 weeks of gestation. The diagnosis requires that the patients have: elevated blood pressure (systolic $\geq 140$ or diastolic $\geq 90 \mathrm{~mm} \mathrm{Hg}$ ), previously normal blood pressures, no protein in the urine, and no manifestations of preeclampsia-eclampsia. Preeclampsia is defined as elevated blood pressure after 20 weeks of gestation ( $\geq 140 \mathrm{~mm} \mathrm{Hg}$ systolic or $\geq 90 \mathrm{~mm}$ $\mathrm{Hg}$ diastolic) plus proteinuria (>0.3 g/24 hours). Severe preeclampsia is defined as any of the following: Markedly 
elevated blood pressure measurements (systolic $\geq$ $160 \mathrm{~mm} \mathrm{Hg}$ or diastolic $\geq 110 \mathrm{~mm} \mathrm{Hg}$ ) taken at least 6 hours apart with the patient on bed rest Proteinuria $(\geq$ $5 \mathrm{~g} / 24$ hours or $\geq 3+$ on two random samples 4 hours apart). Eclampsia is the development of convulsions in a preexisting pre-eclampsia or it may appear unexpectedly in a patient with minimally elevated blood pressure and no proteinuria ${ }^{3}$.

Hypertensive disorders represent a significant proportion of maternal deaths worldwide. Such deaths account $9.1 \%$, and $25.7 \%$ in South Asia, and Latin America respectively ${ }^{4}$ and case fatality rates are higher in less developed countries than developed countries, ranging from $26.3 \%$ in South Africa to $1.8 \%$ in the United Kingdom ${ }^{5}$.Between 2011 and 2013, pregnancy-induced hypertension caused $7.4 \%$ of maternal deaths in the United States ${ }^{6}$.In Nepal, preeclampsia-eclampsia is the second leading direct cause of maternal mortality at the community level after post partum hemorrhage. It is the number one direct cause of maternal death in health facilities which accounts for $30 \%$ of maternal deaths. The Nepal Maternal Mortality and Morbidity Study $2008 / 2009$ revealed that $21 \%$ maternal death was due to eclampsia, which was increased from $14 \%$ in $1998^{7}$. Fetal complications associated with HDP especially preeclampsia and eclampsia are IUGR, oligohydramnios, preterm delivery, non reassuring fetal heart rate patterns during labor, low APGAR scores at birth and NICU admission ${ }^{8}$. This study was carried out to identify the maternal and perinatal outcome of hypertensive disorders among mothers in a tertiary hospital setting of Nepal.

\section{METHODS}

A hospital based prospective study was carried out to assess the maternal and perinatal outcome of hypertensive disorders in pregnancy. Ethical approval for the study was obtained from the institutional review committee of Kathmandu Medical College Teaching Hospital (KMCTH). One hundred pregnant women with the diagnosis of hypertension in pregnancy, admitted in obstetric ward of KMCTH were purposively selected for the study. Permission for data collection was taken from head of the department of Obstetrics/Gynaecology and written informed consent was taken from each respondent. One-on-one interview technique was used to collect the necessary data by using pre-designed structured questionnaire. The data collection period was from December 2015 to January 2017. All the baseline information of each woman was gathered at the time of admission and women were continuously followed-up until discharged from the hospital after delivery to get information regarding outcome. According to severity of blood pressure and proteinuria presence in the respondents, hypertensive disorders were categorized as: chronic hypertension (presence of high blood pressure before 20 weeks of pregnancy), gestational hypertension (systolic $\geq 140$ or diastolic $\geq 90 \mathrm{mmHg}$, after 20 weeks of pregnancy, and no protein in the urine), preeclampsia (elevated blood pressure after 20 weeks of gestation plus proteinuria 1+dipstickor more) and eclampsia (preeclampsia with convulsion). Similarly, blood pressure was characterized as mild (140-159/90$99 \mathrm{~mm}$ of $\mathrm{Hg}$ ), moderate (160/179/100-109 mm of Hg) and severe ( $\geq 180 / \leq 110 \mathrm{~mm}$ of $\mathrm{Hg}$ ). Collected data were coded and entered in Microsoft excel 2007 and data were analyzed by using statistical package for social sciences (SPSS) 20 version. Categorical variables were analyzed using frequency distribution and percentages and continuous variables were expressed in means and standard deviations.

\section{RESULTS}

Socio-demographic characteristics of the respondents are presented in table 1 . Two third (66\%) of the respondents were between the age group of 2030 years with the mean age 27.71 years(range18-39 years). On the basis of resident, most (96\%) of the respondents were from urban areas. Most (91\%) of the respondents were Hindu and majority (58\%) of the respondents were belong to nuclear family. Majority (58\%) of the respondents had obtained secondary to higher secondary level education and more than three fourth $(77 \%)$ of the respondents were home makers by occupation. Most (94\%) of the respondents were non vegetarian regarding the food pattern.

On the basis of obstetrical characteristics, half (50\%) of the respondents were primigravida, all in all respondents had done antenatal visits and most (93\%) of the respondents had gone for antenatal visit more than four times and around $70 \%$ of women were admitted after 37 weeks of gestation. Most (88\%) of the respondents, had no family history of hypertension in pregnancy and almost all (98\%) of the respondents were diagnosed to have hypertensive disorder in third trimester of pregnancy. According to grading of blood pressure, $87 \%$ of the respondents had mild hypertension and $81 \%$ were taking antihypertensive drugs. On the basis of category of hypertensive disorder in pregnancy, $80 \%$ respondents had gestational hypertension, $16 \%$ had preeclampsia, two percent had eclampsia and remaining two had chronic hypertension (Table 2). 
In around $60 \%$ of the respondents, delivery was done by induction of labor, 52\% had normal vaginal delivery, $46 \%$ underwent caesarian section and two percent had vacuum delivery. One respondent had ante-partum hemorrhage, $11 \%$ respondents had postpartum hemorrhage and one had developed hemolysis, elevated liver enzyme, low platelets count (HELLP) syndrome. Nine women were admitted to intensive care unit (ICU) for close monitoring and supervision (Table 3). Fortunately, there was not any maternal mortality.

Table 1: Socio-demographic characteristics of the respondents $(n=100)$

\begin{tabular}{|c|c|c|}
\hline Variables & Frequency & Percentage \\
\hline \multicolumn{3}{|l|}{ Age (years) } \\
\hline Below 20 & 2 & 2.0 \\
\hline $20-30$ & 66 & 66.0 \\
\hline $30-40$ & 32 & 32.0 \\
\hline \multicolumn{3}{|l|}{ Mean \pm S.D $=27.71 \pm 4.924$} \\
\hline \multicolumn{3}{|l|}{ Resident } \\
\hline Rural & 4 & 4.0 \\
\hline Urban & 96 & 96.0 \\
\hline \multicolumn{3}{|l|}{ Religion } \\
\hline Hindu & 91 & 91.0 \\
\hline Buddhist & 5 & 5.0 \\
\hline Others & 4 & 4.0 \\
\hline \multicolumn{3}{|l|}{ Type of family } \\
\hline Nuclear & 58 & 58.0 \\
\hline Joint & 42 & 42.0 \\
\hline \multicolumn{3}{|l|}{ Education } \\
\hline Non-formal education & 4 & 4.0 \\
\hline Primary level & 15 & 15.0 \\
\hline Secondary level & 18 & 18.0 \\
\hline Higher secondary level & 40 & 40.0 \\
\hline Bachelor and above & 28 & 28.0 \\
\hline \multicolumn{3}{|l|}{ Occupation } \\
\hline Homemaker & 77 & 77.0 \\
\hline Private employee & 15 & 15.0 \\
\hline Government employee & 4 & 4.0 \\
\hline Business & 4 & 4.0 \\
\hline \multicolumn{3}{|l|}{ Food Pattern } \\
\hline Vegetarian & 6 & 6.0 \\
\hline Non Vegetarian & 94 & 94.0 \\
\hline
\end{tabular}

Regarding perinatal outcome of hypertensive disorders, $17 \%$ babies were born preterm, 13\% babies had low birth weight, 54\% babies had low APGAR score at birth and seven percent babies had birth asphyxia. Likewise, five percent babies were delivered still birth and one percent had early neonatal death. One fourth (25\%) neonates were admitted in neonatal intensive care unit for further management (Table 4).

\section{Table 2: Distribution of the respondents according to obstetrics and medical history}

\begin{tabular}{|lcc|}
\hline Variables & Frequency & Percentage \\
\hline Gravidity & & \\
\hline Primi & 50 & 50.0 \\
\hline Multi & 50 & 50.0 \\
\hline Weeks of Gestation & & \\
\hline Below 37 & 31 & 31.0 \\
\hline Above 37 & 69 & 69.0 \\
\hline
\end{tabular}

\section{Number of antenatal visits}

$\begin{array}{ccc}<4 \text { times } & 7 & 7.0 \\ >4 \text { times } & 93 & 93.0\end{array}$

\section{Family history of hypertension}

$\begin{array}{lll}\text { Yes } & 12 & 12.0 \\ \text { No } & 88 & 88.0\end{array}$

\section{Severity of hypertension}

$\begin{array}{lcc}\text { Mild* } & 87 & 87.0 \\ \text { Moderate** }^{* *} & 12 & 12.0 \\ \text { Severe*** }^{* *} & 1 & 1.0\end{array}$

\section{Antihypertensive drugs used}

$\begin{array}{lll}\text { Yes } & 81 & 81.0 \\ \text { No } & 19 & 19.0\end{array}$

\section{Category of HDP}

\begin{tabular}{lcc} 
Gestational hypertension & 80 & 80.0 \\
Preeclampsia & 16 & 16.0 \\
Eclampsia & 2 & 2.0 \\
Chronic hypertension & 2 & 2.0 \\
Grading of edema & & \\
Nil & 62 & 62.0 \\
Mild (Grade+) & 36 & 36.0 \\
Moderate (Grade++) & 2 & 2.0 \\
\hline
\end{tabular}

*140-159/90-99**160/179/100-109*** $\geq 180 / \leq 110 \mathrm{~mm}$ of Hg 
Table 3: Obstetrical / maternal outcome of hypertensive disorders of pregnancy

\begin{tabular}{|lcc|}
\hline Variables & Frequency & Percentage \\
\hline $\begin{array}{l}\text { Type of Delivery } \\
\text { Normal vaginal }\end{array}$ & 52 & 52.0 \\
\hline Caesarean Section & 46 & 46.0 \\
\hline $\begin{array}{l}\text { Vacuum Delivery } \\
\text { Gestational age of Delivery }\end{array}$ & 2 & 2.0 \\
\hline Term & 83 & 83.0 \\
\hline Preterm & 17 & 17.0 \\
\hline Induction of Labour & & \\
\hline Yes & 59 & 59.0 \\
\hline No & 41 & 41.0 \\
\hline Maternal Morbidity & & \\
\hline HELLP* Syndrome & 1 & 1.0 \\
\hline APH $^{* *}$ & 1 & 1.0 \\
\hline PPH $^{* * *}$ & 11 & 11.0 \\
\hline ICU*** admission & 9 & 9.0 \\
\hline
\end{tabular}

*Hemolysis, Elevated Liver enzyme, Low platelet counts,

**Ante-partum Hemorrhage

*** Post-partum Hemorrhage. ${ }^{* * * *}$ Intensive Care Unit

\section{Table 4: Perinatal outcome of hypertensive disorders of pregnancy}

\begin{tabular}{lcc|}
\hline $\begin{array}{l}\text { Variables } \\
\text { Perinatal Outcome }\end{array}$ & Frequency & Percentage \\
\hline $\begin{array}{l}\text { Premature birth } \\
\text { Low birth weight }(< \\
\text { 2500gm) }\end{array}$ & 17 & 17.0 \\
\hline $\begin{array}{l}\text { Low APGAR* score }(<6 / 10) \\
\text { at birth }\end{array}$ & 13 & 7.0 \\
\hline Birth asphyxia & 54 & 54.0 \\
\hline Stillbirth & 7 & 5.0 \\
\hline NICU** admission & 5 & 5.0 \\
\hline $\begin{array}{l}\text { Early neonatal death } \\
\text { *Appearance, Pulse, Grimace, } \\
\text { **Neonatal Intensive Care Unit }\end{array}$ & 25 & 25.0 \\
\hline
\end{tabular}

\section{DISCUSSION}

Hypertensive disorders of pregnancy are responsible for significant maternal and perinatal morbidity and are the second leading cause of maternal mortality ${ }^{9}$. Eclampsia is the leading direct cause of maternal mortality in Nepal, occurring in 1 in 25 women and resulting in an estimated $21 \%$ of maternal deaths annually ${ }^{7}$. The condition is also associated with adverse neonatal outcomes, including higher rates of neonatal intensive care unit admission and length of stay, small for gestational age, stillbirth, and mortality ${ }^{10}$. Because termination of pregnancy is the definitive management of gestational hypertension and eclampsia, such complications remain the leading cause of provider-initiated preterm delivery globally ${ }^{11}$.

Studies have shown that risk factors of hypertensive disorders of pregnancy are early pregnancy $\quad<20$ years) or advanced age pregnancy ( $>40$ years) and first pregnancy. But in this study, majority of respondents were between the age group of 20-30 years and half proportion of respondents were multi-gravid. $80 \%$ respondents had gestational hypertension, 16\% had preeclampsia, two percent had eclampsia and remaining two had chronic hypertension. Slightly different findings were observed in a study conducted in a tertiary hospital of India in which it was mentioned that among hypertensive disorders, $50.2 \%$ were pre eclampsia, $35.7 \%$ eclampsia, $12.5 \%$ were gestational hypertension and rest was chronic hypertension ${ }^{12}$.

In the present study, $46 \%$ hypertensive women underwent caesarian section delivery, one percent respondent had ante-partum hemorrhage, $11 \%$ respondents had postpartum hemorrhage, one percent had developed HELLP syndrome and nine women were admitted to intensive care unit. The findings are comparable with a study done at Korle Bu Teaching Hospital, Ghana which revealed that overall, $45.7 \%$ women with hypertensive disorders in pregnancy delivered by cesarean, $4.3 \%$ had placental abruption, $0.8 \%$ had HELLP syndrome, and $5.7 \%$ were admitted to the intensive care unit ${ }^{13}$.

Regarding perinatal outcome of hypertensive disorders, the findings of this study revealed that $17 \%$ babies were born preterm, 13\% babies had low birth weight, five percent babies were delivered still birth and one percent had early neonatal death which is consistent with the findings of a study done at Shree Birendra Hospital in which among 100 hypertensive disorders of pregnancy, the incidence of preterm birth was $13 \%, 15$ babies had low birth weight $(<2.5 \mathrm{Kg})$ and total four were stillbirths ${ }^{14}$.

This study was carried out in only one hospital with very small sample size. Study unit was selected by using purposive sampling technique. So, the findings of the study may not represent the whole population. Community based similar studies can be conducted in a large scale. 


\section{CONCLUSION}

On the basis of findings, it can be concluded that maternal outcome of hypertensive disorders of pregnancy was not significantly adverse but perinatal outcome was found to be adverse. Overall, management of hypertensive disorders of pregnancy in KMCTH was satisfactory. Adverse effects of hypertensive disorders can be minimized by appropriate management. So, prompt management is required to prevent its complications among mothers and to reduce perinatal morbidities and mortalities.

\section{ACKNOWLEDGEMENT}

We are thankful to the Department of Obstetrics and Gynaecology of Kathmandu Medical College Teaching Hospital for helping us in carrying out this study. Our special thanks go to all the respondents of the study for their kind cooperation.

\section{REFERENCES}

1. Ca Lippincott W \& Wilkins. Hypertensive disorders in pregnancy. 8thEd. in: Barton JR, et al. Manual of Obstetrics. Wolters Kluver Health, Philadelphia, USA; 2014:183-5.

2. Sherri AL, Chi PD, Gabisella P. Pre-eclampsia and eclampsia. Revisited S. Afro Med J [Internet] 2003 [cited 2016 Jan 5] 98: 891-9. Available from: http:// jiom.com.np/index.php/jiomjournal/article/ download/758/700

3. Report of the National High Blood Pressure Education Program Working Group on High Blood Pressure in Pregnancy. Am J Obstet Gynecol. [Internet] 2000 [cited 2016 Jan 6] 183(1):S1-S22. Available from: https://www.ncbi.nlm.nih.gov/

4. Khan KS, Wojdyla D, Say L, Gulmezoglu AM, Van Look PF.WHO analysis of causes of maternal death:a systematic review. Lancet. [Internet] 2006 [cited 2016 Jan 6] 1; 367(9516):1066-74.Available from: https:// www.ncbi.nlm.nih.gov/pubmed/16581405

5. Langer A, Villar J, Tell K, Kim T, Kennedy S. Reducing eclampsia-related deaths--a call to action. Lancet. [Internet] 2008 [cited 2016 Jan 9] 1;371(9614):7056.Available from: https://www.ncbi.nlm.nih.gov/ pubmed/18313488

6. Reproductive Health: Pregnancy Mortality Surveillance System. Centers for Disease Control and Prevention. [Internet].2017 Jan 31 [cited 2017 Mar 8]. Available from: https://www.cdc. gov/reproductivehealth/maternalinfanthealth/ pmss.

7. Pradhan A, Suvedi BK, Barnett S, Sharma SK, Puri M, Poudel $P$, et al. Nepal maternal mortality and mortality study 2008/2009. Kathmandu, Nepal:Family health division, department of health services, ministry of health and population; 2010.
8. Tavassoli F, Ghasemi M, Ghomian N, Ghorbani A, Tavassoli $S$, et al. Maternal and perinatal outcome in nulliparious women complicated with pregnancy hypertension J Pak Med Assoc[Internet] 2010. [cited 2017 Jan 7] 60(9): 707-10.Available from:http:// medcraveonline.com/OGIJ/OGIJ-06-00229. php

9. Maternal Mortality. National \& International Perspectives In: The Year book of Obstetrics \& gynecology; 7thed.London: Blackwell 2007; 22735.

10. Ananth CV, Basso O. Impact of pregnancy-induced hypertension on stillbirth and neonatal mortality. Epidemiol Camb Mass. 2010; 21:118-23. https://doi. org/10.1097/EDE.0b013e3181c297af

11. Morisaki N, Togoobaatar G, Vogel JP, Souza JP,Rowland Hogue CJ, Jayaratne K, Ota E, Mori R. a secondary analysis of the World Health Organization Multicountry survey on maternal and newborn health. BJOG Int J Obstet Gynaecol. 2014; 121(Suppl 1):101-9. https://doi.org/10.1111/14710528.12631

12. Sharma C, Gupta S, Tyagi M, Mani P, Dhingra J. Maternal \& Perinatal outcome in Hypertensive Disorders of Pregnancy in a Tertiary Care Hospital in Northern India. Obstet Gynecol Int J 2017; 6(6). https://doi.org/10.15406/ogij.2017.06.00229

13. Bonsaffoh Kwame Adu-, Samuel A; Obd, Joseph D. Seffah. Maternal outcomes of hypertensive disorders in pregnancy. Obstet Gynecol Int J. 2014; 127(3), December 238-42. https://doi.org/10.1016/j. ijgo.2014.06.010

14. Chand Singh A, Singh Rana S. Fetal Outcome in Hypertensive Disorders of Pregnancy. MJSBH. 2013; Vol.12 (1): 8-10. 